\title{
ESTUDO SOBRE O DESCARTE DE MEDICAMENTOS E EDUCAÇÃO AMBIENTAL NO MUNICÍPIO DE PRESIDENTE PRUDENTE - SP
}

\section{STUDY ON DRUG DISPOSAL AND ENVIRONMENTAL EDUCATION IN THE MUNICIPALITY OF PRESIDENTE PRUDENTE - SP}

\author{
Maurício Oliveira Costa, Renata Cristina Mafra, Diego Ariça Ceccato \\ Universidade do Oeste Paulista, Curso de Engenharia Ambiental e \\ Sanitária, Cidade de Presidente Prudente, Estado de São Paulo. \\ e-mail: maoris titi@hotmail.com .
}

RESUMO - O consumo de medicamentos é primordial para o cuidado da saúde da sociedade, no entanto o fácil acesso a estes está diretamente relacionado ao excesso de medicamentos descartados diariamente no meio ambiente. Em vista disso, foi realizado um levantamento com relação ao descarte irregular de medicamentos no município de Presidente Prudente - SP, o mesmo estudo foi feito com a aplicação de um questionários contendo perguntas referentes a problemática. E os resultados mostraram que $96 \%$ dos entrevistados possuem medicamentos armazenados em suas residências e que $60,21 \%$ deles são descartados como lixo doméstico, além disso, foi realizada uma comparação entre os sexos constatando que as mulheres possuem maior conhecimento em relação aos homens perante aos impactos que o descarte incorreto de medicamentos pode provocar no meio ambiente. Contudo, concluímos que os resultados serão importantes para a elaboração de possíveis propostas de melhoria em relação ao tema na área de estudo.

Palavras-chave: medicamentos; descarte; educação ambiental.

Recebido em: 29/07/2017

Revisado em: 08/08/2017

Aprovado em: 14/08/2017
ABSTRACT - The consumption of medicines is paramount for the health care of the society, however the easy access to them is directly related to the excess of drugs discarded daily in the environment. In view of this, a survey was made regarding the irregular disposal of drugs in the municipality of Presidente Prudente - SP, the same study was done with the application of questionnaires containing questions concerning the problem. And the results showed that $96 \%$ of the interviewees have drugs stored in their homes and that $60.21 \%$ of them are discarded as household waste, in addition, a comparison was made between the sexes, stating that women have greater knowledge regarding men before to the impacts that improper disposal of medicines can cause in the environment. However, we conclude that the results will be important for the elaboration of possible improvement proposals in relation to the subject in the study area.

Keywords: medicines; discard; environmental education. 


\section{INTRODUÇÃO}

Segundo a Agência Nacional de Vigilância Sanitária (ANVISA), medicamentos são produtos tecnicamente controlados e elaborados para diagnosticar, prevenir, curar enfermidades e/ou aliviar seus sintomas (ANVISA, 2010), tanto em seres humanos quanto em animais. $\mathrm{O}$ descarte incorreto de medicamentos é um problema de saúde pública que envolve órgãos de vigilância sanitária e ambiental atuantes na questão dos impactos destes resíduos sobre a saúde humana e o meio ambiente. Segundo Falqueto, Kligerman e Assumpção (2010), estes órgãos possuem atuações em esferas distintas, porém com o mesmo objetivo de conservação da saúde pública e ambiental por meio de medidas de controle da oferta de medicamentos à população, seus tratamentos e destinação final.

No Brasil, apesar da ANVISA estabelecer, através da Resolução RDC $306 / 2004$, que os estabelecimentos de serviços de saúde devem dispor de Planos de Gerenciamentos de Resíduos de Serviços de Saúde, muitos locais não possuem estes planos e os resíduos de serviços de saúde (RSS) acabam sendo descartados como resíduos sólidos urbanos (RSU) sem tratamento prévio. Dentre os principais métodos de tratamento dos RSS estão os processos térmicos, como a autoclavagem e a incineração, utilizados em $64,5 \%$ dos resíduos no ano de 2013. Ainda neste ano, $33,1 \%$ dos RSS foram destinados em aterros sanitários, aterros em valas e lixões (ABRELPE, 2013).

Os medicamentos formam um subgrupo dentro dos resíduos de serviços de saúde e pode-se considerar que grande parte dos medicamentos vencidos ou resíduos pósconsumo também são descartados de maneira inadequada. No município de Catanduva-SP, $61,35 \%$ da população descarta os medicamentos vencidos ou resíduos pósconsumo no lixo doméstico (MAIA; GIORDANO, 2012), em Santos-SP, 71\% da população tem o mesmo hábito (GASPARINI; GASPARINI; FRIGIERI, 2011) e em CampinasSP essa porcentagem chega a $88,6 \%$ (UEDA, 2009).

Segundo Rocha et al. (2009) a grande maioria dos medicamentos descartados são da forma sólida o que aumenta gradativamente o seu tempo de detenção no meio ambiente, podendo chegar as estações de tratamento, onde de acordo com Bila e Dezotti (2003, 2007) estas substâncias não são completamente removidas.

A importância do tema e os números revelados pelas pesquisas mostram que é fundamental a adoção de campanhas de sensibilização e políticas de educação ambiental nos municípios. Essas ações têm como objetivo examinar estas questões do ponto de vista local e regional, avaliando suas 
causas, consequências e complexidades, tanto no que diz respeito à saúde pública quanto ao meio ambiente.

\section{METODOLOGIA}

\section{Área de Estudo}

O estudo foi realizado em diferentes pontos da cidade de Presidente Prudente, município localizado no estado de São Paulo, situado a $600 \mathrm{~km}$ da Capital. Os entrevistados foram escolhidos de forma aleatória, não seguindo nenhum padrão geográfico.

Figura 1. Localização do município de Presidente Prudente - SP.

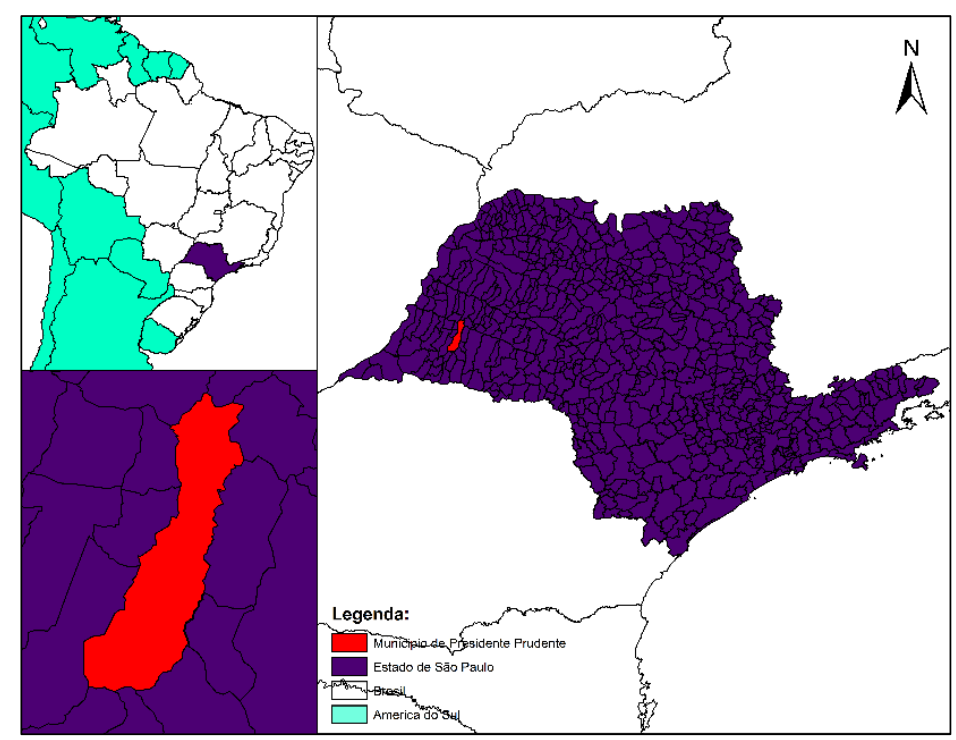

Fonte: IBGE (2014). Modificado pelo autor.

\section{População Amostral}

Baseando-se em um cálculo amostral (GASPARINI; GASPARINI; FRIGIERI, 2011) e considerando que a cidade de Presidente Prudente contém uma população aproximada de 220.599 habitantes (IBGE, 2014), foi delimitada uma população amostral equivalente a 193 pessoas, visando uma margem de erro amostral de até $2 \%$.

Aplicação de Questionário
O processo contou com um questionário no qual teve em esboço a idade do habitante, sexo, nível de escolaridade, renda familiar, além de perguntas que remetem a questões referentes ao descarte de fármacos pela população local no meio ambiente (MAIA, 2012). O Questionário pode ser visto no Anexo-1.

\section{Critérios de Inclusão e Exclusão}

Os critérios de inclusão para a participação na pesquisa foram residir na 
cidade de Presidente Prudente e ter idade mínima de dezoito anos. Foram excluídos aqueles que não aceitaram participar da pesquisa e os participantes que não concordaram em assinar o TCLE (Termo de Consentimento Livre e Esclarecido). Após o projeto ter sido aprovado pelo Comitê de Ética em Pesquisa da Unoeste de CAAE $n^{\circ}$ 50581915.8.0000.5515, se deu início ao levantamento de campo.

\section{RESULTADOS E DISCUSSÃO}

Seguindo o número amostral de 193 pessoas pode-se concluir que dentre os entrevistados $96 \%$ disseram ter medicamentos em sua residência, já $4 \%$ dos entrevistados disseram não fazer uso de medicamentos constantemente, por isso não possuem os mesmos em casa, a, Figura 2 mostra os resultados citados.

Figura 2. Entrevistados que possuem medicamentos em suas residências.

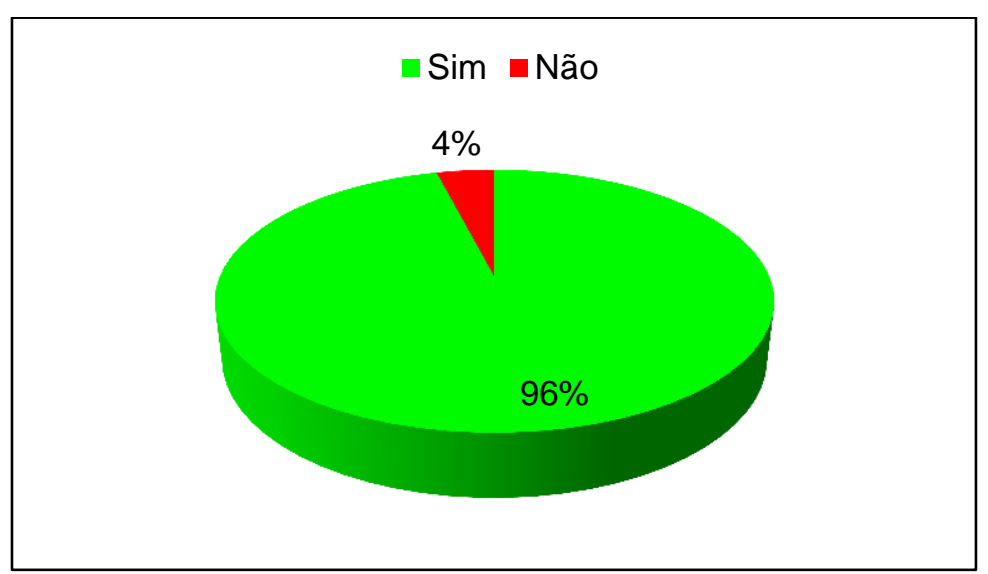

Fonte: Pesquisa de Campo (2017).

Segundo a ANVISA (2010) o prazo de validade de um medicamento corresponde ao tempo durante o qual o produto poderá ser usado, que é caracterizado como período de vida útil e fundamentada nos estudos de estabilidade específicos (ANVISA, 2010). Quando ocorre a violação, os fármacos podem ter sua estabilidade alterada devido a fatores ambientais como (luz, umidade, oxigênio, dentre outros) (GASPARINI; GASPARINI; FRIGIERI, 2011).
Dessa forma foi aplicada a seguinte pergunta aos entrevistados "Possui o habito de observar o aspecto/aparência dos medicamentos antes de utiliza-lo", os dados recolhidos mostram que dentre os entrevistados $76 \%$ afirmam observar o aspecto/aparência e a data de validade antes de utilizar o medicamento, porém 24\% afirmam não ter o hábito de realizar esta prática (Figura 3). Esses dados mostram estatisticamente que se tem um número considerável de pessoas que não realizam a 
prática descrita acima, no entanto, ingerir um medicamento fora do prazo de validade pode causar sérios danos à saúde.

Segundo Schenkel, Fernandes e Mengue (2005), o Brasil possui um intenso número de intoxicações de crianças por medicamentos vencidos. O fato viabiliza e enfatiza a importância de se observar os medicamentos antes de utiliza-los.

Figura 3. Sobre possuírem o hábito de observar o aspecto/aparência e a data de validade do medicamento antes de consumi-lo.

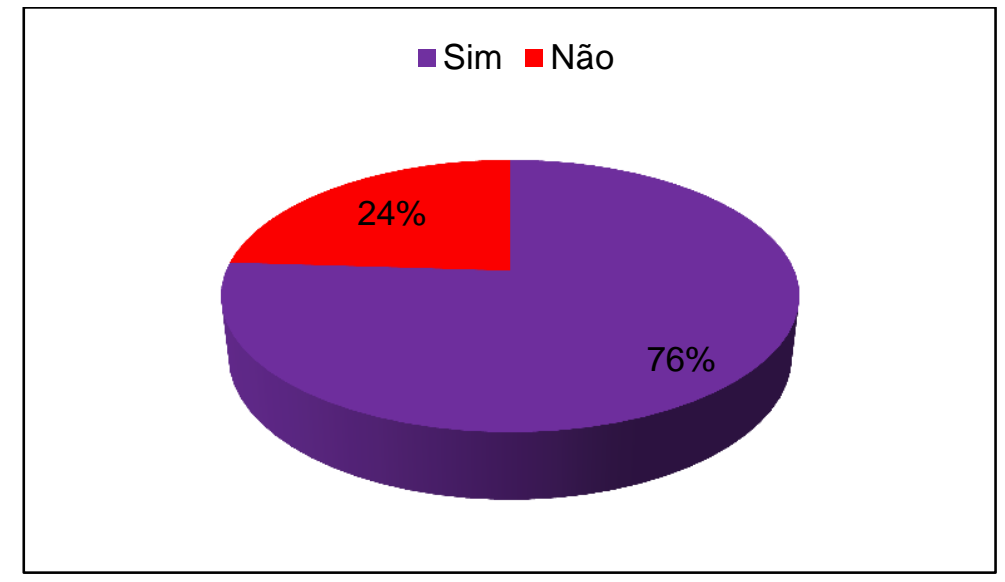

Fonte: Pesquisa de Campo (2017).

O descarte inadequado de medicamentos é uma problemática a ser posta em questão, pois muitas vezes acreditamos que o descarte incorreto é realizado pelas pessoas por falta de informações e de divulgação para com os problemas ambientais que os mesmos podem estar causando no meio ambiente ao descartar os fármacos em lixos ou córregos.

De acordo com os resultados coletados $60,21 \%$ dos entrevistados afirmaram descartar os medicamentos no lixo, isso mostra uma falta de educação e consciência ambiental para com a população do município de Presidente Prudente, e muitas vezes a falta da implementação de Logística Reversa nos estabelecimentos, bem como farmácias e postos de saúde, que foram algumas das principais causas destacadas pelos entrevistados em relação à forma de descarte de medicamentos. A Figura 4 mostra os resultados obtidos na pesquisa de campo. 
Figura 4. O que os entrevistados costumam a fazer com as sobras de medicamentos.

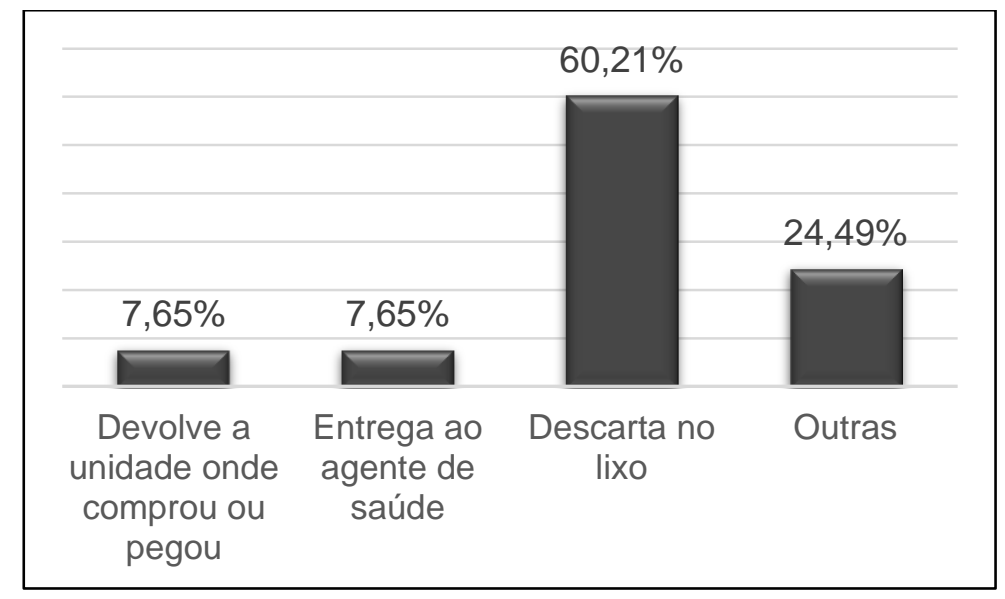

Fonte: Pesquisa de Campo (2017).

Segundo a Lei $\mathrm{N}^{\circ} 9.795$ de 27 de abril de 1999 que institui a Política Nacional de Educação Ambiental, entende-se por educação ambiental:

Os processos por meio dos quais o indivíduo e a coletividade constroem valores sociais, conhecimentos, habilidades, atitudes e competências voltadas para a conservação do meio ambiente, bem de uso comum do povo, essencial à sadia qualidade de vida e sua sustentabilidade.

Tendo em vista a Política Nacional de Educação Ambiental foi realizada uma pergunta aos entrevistados, para avaliar o nível de conhecimento da população para com a problemática, a pergunta dizia se os entrevistados estavam cientes de que o descarte incorreto de medicamentos podem ocasionar impactos ambientais, e dentre os resultados $83 \%$ dos entrevistados afirmaram saber que o descarte incorreto e irregular de medicamentos pode sim ocasionar impactos ambientais, no entanto $17 \%$ dos entrevistados disseram não saber que a ação poderia ocasionar impactos no meio ambiente, o que mostra significativamente uma falta de conhecimentos básicos para com a população a Figura 5 mostra os resultados obtidos com a realização da pergunta. 
Figura 5. Respostas sobre os entrevistados estarem cientes de que os descartes incorretos de medicamentos podem provocar impactos ambientais.

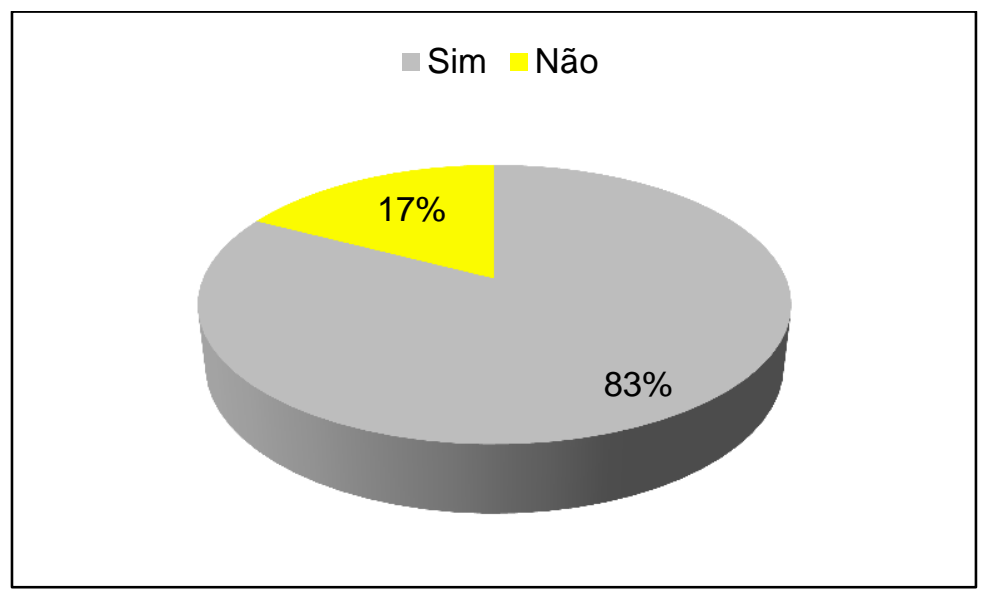

Fonte: Pesquisa de Campo (2017).

O estudo dos dados coletados com os questionários permite uma abordagem mais ampla e direta das problemáticas envolvidas com relação ao descarte de medicamentos na cidade de Presidente Prudente - SP. Após o termino da aplicação dos questionários foi elaborado então um estudo estatístico com os dados coletados em campo, e feita a realização de um quadro visando à comparação das perguntas feitas mediante a população em relação à renda e ao nível de escolaridade de cada entrevistado.

Os quadros foram divididos por sexo relacionando a renda e a escolaridade, onde cada qual representa o número de respostas por sexo em relação a uma renda na Figura 8 e Figura 9, e a uma escolaridade na Figura 6 e Figura 7. 
Figura 6. Levantamento das respostas de acordo com a escolaridade masculina.

\begin{tabular}{|c|c|c|c|c|c|c|c|c|c|c|}
\hline \multirow{2}{*}{ ESCOLARIDADE } & \multicolumn{2}{|c|}{ Pergunta - 1} & \multicolumn{2}{|c|}{ Pergunta - 2} & \multicolumn{4}{|c|}{ Pergunta - 3} & \multicolumn{2}{|c|}{ Pergunta - 4} \\
\hline & Sim & Não & Sim & Não & Devolve & Entrega & Descarta & Outras & Sim & Não \\
\hline $\begin{array}{l}\text { Ensino Fundamental } \\
\text { Completo }\end{array}$ & - & - & - & - & - & - & - & - & - & - \\
\hline $\begin{array}{l}\text { Ensino Fundamental } \\
\text { Incompleto }\end{array}$ & $100 \%$ & - & $58 \%$ & $42 \%$ & $25 \%$ & $8,40 \%$ & $33,30 \%$ & $33,30 \%$ & $92 \%$ & $8 \%$ \\
\hline Ensino Medio Completo & $95,23 \%$ & $4,77 \%$ & $81 \%$ & $19 \%$ & $9,50 \%$ & $14,29 \%$ & $52,40 \%$ & $23,81 \%$ & $95,23 \%$ & $4,77 \%$ \\
\hline $\begin{array}{l}\text { Ensino Medio } \\
\text { Incompleto }\end{array}$ & $100 \%$ & - & $70 \%$ & $30 \%$ & $10 \%$ & $10 \%$ & $40 \%$ & $40 \%$ & $90 \%$ & $10 \%$ \\
\hline $\begin{array}{l}\text { Ensino Superior } \\
\text { Completo }\end{array}$ & $92 \%$ & $8 \%$ & $100 \%$ & - & - & $8,33 \%$ & $50 \%$ & $41,67 \%$ & $83,33 \%$ & $16,67 \%$ \\
\hline $\begin{array}{l}\text { Ensino Superior } \\
\text { Incompleto }\end{array}$ & $90 \%$ & $10 \%$ & $55 \%$ & $45 \%$ & - & $7,50 \%$ & $62,50 \%$ & $30 \%$ & $70 \%$ & $30 \%$ \\
\hline Nenhum & $100 \%$ & - & $100 \%$ & - & - & - & - & $100 \%$ & - & $100 \%$ \\
\hline
\end{tabular}

Fonte: Pesquisa de Campo (2017).

De acordo com os dados expressos na Figura 6 é possível concluir que a maioria dos entrevistados do sexo masculino em relação a sua escolaridade possuem ensino superior incompleto, onde $92 \%$ afirmam ter medicamentos em sua residência e apenas 8\% afirmam não possuírem medicamentos. Além disso, $45 \%$ das pessoas do sexo masculino confirmaram não possuírem o hábito de verificar os medicamentos antes de utiliza-los, sendo que $55 \%$ afirmaram possuir o hábito de verificar o medicamento antes do consumo, isso pode ocorrer por conta de a maioria dos entrevistados dizerem diante da entrevista que apenas pegam a quantidade correta de medicamentos para o consumo, o que faz com que diminua a quantidade de medicamentos em casa e as chances de eles ficarem vencidos com o tempo, porém não inibe a possibilidade de encontrarem ou até receberem medicamentos já vencidos.

Com relação à forma de descarte de medicamentos é possível se concluir que a maioria dos entrevistados do sexo masculino afirmaram descartar os mesmos no lixo, onde $62,5 \%$ dos entrevistados que descartam os medicamentos no lixo possuem o ensino superior incompleto, $52,4 \%$ dos entrevistados possuem o ensino médio completo e $50 \%$ dos entrevistados com ensino superior completo, talvez os altos números se deva a falta de pontos de descarte de medicamentos na cidade ou até falta de divulgação, o que afirmaram algumas pessoas diante das entrevistas realizadas em campo. Embora a maioria dos homens entrevistados descartem os medicamentos 
no lixo, são poucos os que procuram meios de descarta-los corretamente.

Quando perguntados sobre o fato de saberem se o descarte incorreto de medicamentos poderia causar impactos ambientais $30 \%$ dos entrevistados com ensino superior incompleto afirmaram não saber sobre o assunto, no entanto $70 \%$ dos homens que possuem ensino superior incompleto afirmaram saber do impacto que a ação poderia causar no meio ambiente, onde também 95,23\% dos entrevistados possuem ensino médio completo e $92 \%$ dos entrevistados possui ensino fundamental incompleto também afirmaram saber do impacto dos medicamentos no meio ambiente o que mostra ser um número favorável.

Figura 7. Levantamento das respostas de acordo com a escolaridade feminina.

\begin{tabular}{|c|c|c|c|c|c|c|c|c|c|c|}
\hline \multirow{2}{*}{ ESCOLARIDADE } & \multicolumn{2}{|c|}{ Pergunta - 1 } & \multicolumn{2}{|c|}{ Pergunta - 2 } & \multicolumn{4}{|c|}{ Pergunta - 3 } & \multicolumn{2}{c|}{ Pergunta - 4 } \\
\cline { 2 - 11 } & Sim & Não & Sim & Não & Devolve & Entrega & Descarta & Outras & Sim & Não \\
\hline $\begin{array}{c}\text { Ensino Fundamental } \\
\text { Completo }\end{array}$ & $100 \%$ & - & $75 \%$ & $25 \%$ & $25 \%$ & - & $75 \%$ & - & $75 \%$ & $25 \%$ \\
\hline $\begin{array}{c}\text { Ensino Fundamental } \\
\text { Incompleto }\end{array}$ & $94 \%$ & $6 \%$ & $75 \%$ & $25 \%$ & $18,75 \%$ & - & $81,25 \%$ & - & $69 \%$ & $31 \%$ \\
\hline $\begin{array}{c}\text { Ensino Medio } \\
\text { Completo }\end{array}$ & $100 \%$ & - & $94 \%$ & $6 \%$ & $6,25 \%$ & - & $50 \%$ & $43,75 \%$ & $88 \%$ & $12 \%$ \\
\hline $\begin{array}{c}\text { Ensino Medio } \\
\text { Incompleto }\end{array}$ & $75 \%$ & $25 \%$ & $100 \%$ & - & $25 \%$ & $25 \%$ & $50 \%$ & - & $75 \%$ & $25 \%$ \\
\hline $\begin{array}{c}\text { Ensino Superior } \\
\text { Completo }\end{array}$ & $100 \%$ & - & $100 \%$ & - & $37,50 \%$ & $25 \%$ & $37,50 \%$ & - & $100 \%$ & - \\
\hline $\begin{array}{c}\text { Ensino Superior } \\
\text { Incompleto }\end{array}$ & $100 \%$ & - & $83 \%$ & $17 \%$ & - & $7,69 \%$ & $67,30 \%$ & $25 \%$ & $92 \%$ & $8 \%$ \\
\hline Nenhum & $100 \%$ & - & - & $100 \%$ & $50 \%$ & - & $50 \%$ & - & - & $100 \%$ \\
\hline
\end{tabular}

Fonte: Pesquisa de Campo (2017).

Assim como na escolaridade do sexo masculino prevalece 0 ensino superior incompleto na escolaridade do sexo feminino também, sendo 50,98\% de um total de 102 mulheres entrevistadas.

Com relação aos dados da Figura 7 é possível concluir que das $50,98 \%$ das mulheres com ensino superior incompleto todas possuem medicamentos em sua residência, assim como nos outros níveis de escolaridade, sendo apenas uma mulher com ensino médio completo e uma mulher com ensino fundamental incompleto afirmam não possuírem medicamentos em casa.

Sobre o fato de verificarem os medicamentos antes de utiliza-los a grande 
maioria das mulheres entrevistadas afirmam fazer a verificação, onde apenas $17 \%$ das mulheres com ensino superior incompleto e $25 \%$ das mulheres com ensino fundamental incompleto e ensino fundamental completo afirmaram não realizarem a verificação, talvez o mesmo ato da não verificação se deva ao fato de as mesmas afirmarem que pegam os medicamentos na quantidade correta que vão consumir para evitar a grande quantidade de medicamentos guardados em casa segundo algumas afirmações feitas diante das entrevistas.

A forma de descarte de medicamentos chama a atenção com relação as mulheres que possuem ensino superior incompleto, pois $67,30 \%$ das mulheres entrevistadas afirmam descartar os medicamentos no lixo, isso significa dizer que em relação ao sexo masculino com o mesmo nível de escolaridade as mulheres descartam mais medicamentos no lixo do que os homens, sendo $67,30 \%$ das mulheres contra $62,5 \%$ dos homens. Além disso, $81,25 \%$ das mulheres entrevistadas que possuem ensino fundamental incompleto e $50 \%$ das mulheres entrevistadas que possuem ensino médio completo também descartam medicamentos no lixo. No entanto, $37,5 \%$ das mulheres com ensino superior completo e $18,75 \%$ das mulheres com ensino fundamental incompleto optam por devolverem ao local onde pegaram ou compraram os medicamentos.

Ao serem perguntadas sobre os impactos que o descarte de medicamentos pode causar no meio ambiente a grande maioria das mulheres afirmam saber sobre o assunto, sendo apenas 31\% mulheres que possuem ensino fundamental incompleto e $8 \%$ das mulheres com ensino superior incompleto afirmando não saber dos possíveis impactos que 0 descarte de medicamentos pode provocar no meio ambiente. Em comparação aos homens 92\% das mulheres com ensino superior incompleto afirmam estarem mais atentas aos impactos ambientais provocados pelo descarte incorreto de medicamentos no meio ambiente, onde apenas $70 \%$ dos homens se mostram atentos a problemática.

Diferentemente da escolaridade, o levantamento das respostas dos questionários de acordo com a renda, possibilita saber e entender o nível de pensamento da população em relação a suas diferentes classes sociais. 
Figura 8. Levantamento das respostas de acordo com a renda masculina.

\begin{tabular}{|c|c|c|c|c|c|c|c|c|c|c|}
\hline \multirow{2}{*}{ RENDA } & \multicolumn{2}{|c|}{ Pergunta - 1} & \multicolumn{2}{|c|}{ Pergunta - 2} & \multicolumn{4}{|c|}{ Pergunta - 3} & \multicolumn{2}{|c|}{ Pergunta - 4} \\
\hline & Sim & Não & Sim & Não & Devolve & Entrega & Descarta & Outras & Sim & Não \\
\hline$R \$ 500$ a $R \$ 1000$ & $93,75 \%$ & $6,25 \%$ & $69 \%$ & $31 \%$ & $12,50 \%$ & $9,38 \%$ & $53,12 \%$ & $25 \%$ & $75 \%$ & $25 \%$ \\
\hline$R \$ 1000$ a $R \$ 1500$ & $93,75 \%$ & $6,25 \%$ & $56 \%$ & $44 \%$ & $6,25 \%$ & $6,25 \%$ & $37,50 \%$ & $50 \%$ & $100 \%$ & - \\
\hline $\mathrm{R} \$ 1500$ a $\mathbf{R} \$ 2000$ & $100 \%$ & - & $80 \%$ & $20 \%$ & - & $20 \%$ & $60 \%$ & $20 \%$ & $90 \%$ & $10 \%$ \\
\hline$R \$ 2000$ a $R \$ 2500$ & $86 \%$ & $14 \%$ & $100 \%$ & - & - & $14 \%$ & $57,14 \%$ & $28,58 \%$ & $71,42 \%$ & $28,58 \%$ \\
\hline$R \$ 2500$ a $R \$ 3000$ & $90,90 \%$ & $9,10 \%$ & $64 \%$ & $36 \%$ & $9,10 \%$ & - & $64 \%$ & $27,27 \%$ & $64 \%$ & $36 \%$ \\
\hline Mais de $\mathbf{R} \$ 3000$ & $94,74 \%$ & $5,26 \%$ & $63 \%$ & $37 \%$ & - & $10,52 \%$ & $47,37 \%$ & $42,10 \%$ & $78,94 \%$ & $21,06 \%$ \\
\hline
\end{tabular}

Fonte: Pesquisa de Campo (2017).

Com relação aos dados levantados sobre a renda masculina, em relação às respostas obtidas pode-se concluir que a maioria dos homens entrevistados possuem uma renda entre $\mathrm{R} \$ 500,00$ e $\mathrm{R} \$ 1.000,00$ reais sendo que $93,75 \%$ afirmam possuir medicamentos em casa e apenas $6,25 \%$ dos homens afirmam não possuírem medicamentos em casa. Além disso, dos homens que possuem renda acima de $\mathrm{R} \$ 3.000,00$ reais $94,74 \%$ afirmam possuir medicamentos em casa.

De acordo com os resultados obtidos nos questionários pode-se afirmar também que $69 \%$ dos homens com renda até $\mathrm{R} \$$ $1.000,00$ reais afirmam verificar os medicamentos antes do consumo, sendo que $31 \%$ afirmam não realizar a verificação antes de utilizar o medicamento, ja em comparação aos entrevistados que recebem acima de $\mathrm{R} \$$
$3.000,00$ reais tem-se uma margem pequena, porém existente, de que $63 \%$ dos homens que possuem renda acima de $\mathrm{R} \$ 3.000,00$ reais verificam os medicamentos antes de utiliza-lo.

O descarte incorreto de medicamentos em relação ás rendas da Figura 8 são bem similares entre si, uma vez que a classe social que mais descarta medicamentos no lixo está entre as que recebem até $\mathrm{R} \$ 1.000,00$ reais $(53,12 \%)$ seguida das que recebem acima de $\mathrm{R} \$$ $3.000,00$ reais $(47,37 \%)$ e das que recebem entre $R \$ 2.500,00$ até $3.000,00$ reais (64\%) sendo a última a mais agravante.

Sobre o fato de conhecerem sobre os possíveis impactos que os descartes incorretos de medicamentos podem provocar no meio ambiente a classe social que recebem até $R \$ 1.000,00$ reais foi a que 
mais se mostrou saber sobre as consequências de um descarte incorreto de medicamento, porém foram os que mais se mostraram não saberem sobre o assunto em quantidades de entrevistados, porém a terceira pior em média de entrevistados com $25 \%$ dos homens dizendo não saberem sobre o assunto, ficando atrás da classe que recebem entre $\mathrm{R} \$ \mathbf{2 . 0 0 0 , 0 0}$ à $\mathrm{R} \$ \mathbf{2 . 5 0 0 , 0 0}$ reais com $28,58 \%$ e da classe que recebe entre $R \$ 2.500,00$ à $R \$ 3.000,00$ reais com 36\% dos entrevistados dizendo não saberem das consequências que o descarte incorreto de medicamentos pode causar no meio ambiente.

Figura 9. Levantamento das respostas de acordo com a renda feminina.

\begin{tabular}{|c|c|c|c|c|c|c|c|c|c|c|}
\hline \multirow{2}{*}{ RENDA } & \multicolumn{2}{|c|}{ Pergunta - 1 } & \multicolumn{2}{|c|}{ Pergunta - 2 } & \multicolumn{4}{|c|}{ Pergunta - 3 } & \multicolumn{2}{c|}{ Pergunta - 4 } \\
\cline { 2 - 11 } & Sim & Não & Sim & Não & Devolve & Entrega & Descarta & Outras & Sim & Não \\
\hline $\mathbf{R} \mathbf{5 0 0}$ a R\$1000 & $95 \%$ & $5 \%$ & $73 \%$ & $27 \%$ & $13,63 \%$ & - & $68,37 \%$ & $18 \%$ & $82 \%$ & $18 \%$ \\
\hline $\mathbf{R} \$ \mathbf{1 0 0 0}$ a R\$1500 & $97 \%$ & $3 \%$ & $93 \%$ & $7 \%$ & $6,91 \%$ & $10,34 \%$ & $65,51 \%$ & $17,24 \%$ & $83 \%$ & $17 \%$ \\
\hline $\mathbf{R} \mathbf{1 5 0 0}$ a R\$2000 & $100 \%$ & - & $73 \%$ & $27 \%$ & $13,33 \%$ & $6,66 \%$ & $46,67 \%$ & $33,34 \%$ & $93 \%$ & $7,00 \%$ \\
\hline $\mathbf{R} \mathbf{2 0 0 0}$ a R\$2500 & $100 \%$ & - & $85 \%$ & $15 \%$ & - & $7,70 \%$ & $84,60 \%$ & $7,70 \%$ & $77 \%$ & $23 \%$ \\
\hline $\mathbf{R} \mathbf{2 5 0 0}$ a R\$3000 & $100 \%$ & - & $100 \%$ & - & - & $20 \%$ & $80 \%$ & - & $100 \%$ & - \\
\hline Mais de R\$3000 & $100 \%$ & - & $82 \%$ & $18 \%$ & $11,78 \%$ & $5,88 \%$ & $52,94 \%$ & $29,40 \%$ & $88 \%$ & $12 \%$ \\
\hline
\end{tabular}

Fonte: Pesquisa de Campo (2017).

A classe social relacionada a renda feminina não é muito diferente da classe masculina, pois a grande maioria das mulheres entrevistadas possuem renda abaixo de $R \$ 1.500,00$ reais o que representa $50 \%$ das mulheres entrevistadas onde a maioria possui renda entre $\mathrm{R} \$ 1.000,00$ à $\mathrm{R} \$$ $1.500,00$ reais das quais $97 \%$ afirmam possuírem medicamentos em casa. Além disso, esta renda tratasse da classe que mais verificam os medicamentos antes de utilizalos sendo $93 \%$ das mulheres entrevistadas, embora $27 \%$ das mulheres que recebem até $\mathrm{R} \$ 1.000,00$ reais afirmam não verificarem os medicamentos antes de utiliza-los para consumo.

Com relação ao descarte incorreto de medicamentos a classe que recebe entre $\mathrm{R} \$$ $2.000,00$ e $R \$ 2.500,00$ reais foi a classe que mais surpreende em relação ao descarte irregular dos mesmos, sendo um total de $85 \%$ das mulheres entrevistados afirmando realizarem o descarte em lixo, seguido das mulheres que recebem entre $\mathrm{R} \$ 2.500,00$ à 
$\mathrm{R} \$ 3.000,00$ reais com um total de $80 \%$ das mulheres entrevistadas e das mulheres que recebem entre $R \$ 500,00$ à $R \$ 1.000,00$ reais com um total de $68,37 \%$ das mulheres entrevistadas na classe afirmando realizar o descarte em lixo.

Das mulheres entrevistadas $23 \%$ das que recebem entre $R \$ 2.000,00$ à $R \$ 2.500,00$ reais afirmam não saberem sobre os possíveis impactos que o descarte irregular e incorreto de medicamentos pode provocar no meio ambiente seguido das mulheres que recebem até $\mathrm{R} \$ \mathbf{1} 1.000,00$ reais com uma média de $18 \%$ e das mulheres que recebem entre $R \$ 1.000,00$ à $R \$ 1.5000,00$ reais com uma média de $17 \%$. No entanto vale ressaltar que as mulheres que recebem entre $\mathrm{R} \$$ $2.000,00$ à $R \$ 2.500,00$ reais são as que se mostraram estarem por dentro dos impactos que $o$ ato pode provocar no meio ambiente com uma média de 100\%, seguido das mulheres que recebem entre $R \$ 1.500,00$ à $\mathrm{R} \$ 2.000,00$ reais com 93\% e as que recebem acima de $\mathrm{R} \$ 3.000,00$ reais com $88 \%$ de mulheres que afirmam saberem dos possíveis impactos que estes podem causar no meio ambiente.

\section{CONCLUSÃO}

Fazendo uma análise exploratória dos dados, concluímos que as mulheres se mostram mais atentas aos homens sobre observarem os medicamentos com relação a aspectos e prazos de validade antes do consumo.

Sobre o descarte irregular de medicamentos (descarte no lixo) pode-se observar que a grande maioria dos entrevistados tanto do sexo masculino quanto do sexo feminino que afirmam descartarem os medicamentos de forma irregular possuem ensino superior incompleto.

Em relação aos entrevistados saberem sobre os possíveis impactos que os descartes irregulares de medicamentos podem provocar no meio ambiente, as mulheres se mostram mais atentas em relação aos homens.

Sobre o descarte irregular de medicamentos (descarte no lixo) pode-se concluir que tanto os entrevistados do sexo masculino quanto os entrevistados do sexo feminino que afirmam descartarem medicamentos de forma irregular, a grande maioria recebem valores superiores a $\quad R \$$ $2.000,00$.

Em relação aos impactos que os descartes irregulares de medicamentos podem provocar no meio ambiente, os entrevistados do sexo masculino que afirmam serem mais leigos em relação a este 
aspecto possuem renda superior a $\mathrm{R} \$$ $3.000,00$.

Os entrevistados do sexo feminino que mais afirmam saberem sobre os possíveis impactos que os descartes irregulares de medicamentos podem ocasionar no meio ambiente possuem renda superior a $\mathrm{R} \$ 2.000,00$.

\section{REFERÊNCIAS}

ABRELPE. Panorama dos Resíduos Sólidos no Brasil. 2013. Disponível em: <http://www.abrelpe.org.br/Panorama/pano rama2013.pdf>. Acesso em: 01 nov. 2014.

ANVISA. O que devemos saber sobre medicamentos? 2010. Disponível em: <http://portal.anvisa.gov.br>. Acesso em: 01 nov. 2014.

BILA, D. M; DEZOTTI, M. Fármacos no meio ambiente. Quim. Nova, v. 26, n. 4, p. 523530, 2003.

BILA, D. M; DEZOTTI, M. Desreguladores endócrinos no meio ambiente: efeitos e consequências. Quim. Nova, v. 30, n. 3, p. 651-666, 2007.

FALQUETO, E.; KLIGERMAN, D. C.; ASSUMPÇÃO, R. F. Como realizar o correto descarte de resíduos de medicamentos? Ciência e Saúde Coletiva, v. 15, supl. 2, p. 3283-3293, 2010. https://doi.org/10.1590/S141381232010000800034

GASPARINI, J.C.; GASPARINI, A. R.; FRIGIERI, M. C. Estudo do descarte de medicamentos e consciência ambiental no município de Catanduva-SP. Ciência \& Tecnologia: FATECJB, v.2, n. 1, p. 38-51, 2011.
IBGE. 2014. Disponível em: $<$ http://cidades.ibge.gov.br/xtras/perfil.php? codmun=354140>. Acesso em: 17 ago. 2014.

MAIA, M.; GIORDANO, F. Estudo da situação atual de conscientização da população de Santos a respeito do descarte de medicamentos. Revista Ceciliana. n. 4, v. 1, p. 24-28, 2012.

ROCHA, B.S. et al. Caracterização dos medicamentos descartados por usuários da farmácia popular do brasil/farmácia-escola da UFRGS. 2009. Disponível em: $<w w w . a c a d e m i a . e d u>$. Acesso em: 04 jan. 2015.

SCHENKEL, E. P.; FERNANDES, L. C.; MENGUE, S. S. Como são armazenados os medicamentos nos domicílios. Acta Farmacêutica Banaerense, Rio Grande do Sul, v. 24, n.2, p. 266-70, 2005.

UEDA, J. et al. Impacto ambiental do descarte de fármacos e estudo da conscientização da população a respeito do problema. Revista Ciências do Ambiente On-Line, v. 5, n. 1, 2009. 